\title{
Obstacles to Nursing Process Implementation
}

\author{
Maryam Izadi Laybidi* \\ Nursing and Midwifery Faculty, Iran University, Iran
}

*Corresponding author: Maryam Izadi Laybidi, Nursing and Midwifery faculty Member, Nursing and Midwifery Faculty, Isfahan of Medical Sciences, Isfahan, Iran

University, Iran.

\author{
Received Date: January 27, 2020 \\ Published Date: February 10, 2020
}

\begin{abstract}
s
The final purpose of a high-quality nursing care is to improve patient situation and return them to society. Increasing the quality of nursing care make patients ready return to their normal life more quickly and prevent them being hospitalized again. One of the most significant approaches to improve the quality of nursing care is to utilize standard of nursing care. Although nursing process is carried out as a nursing standard in the majority of health systems and the advantages and disadvantages have been proved, and also it is included in nursing lessons appropriately, they are not utilized appropriately, done very rarely and nursing care is done traditionally. thus, identifying the barriers facing nursing care process seems essential. Therefore, this study was done to recognize the barriers of correct nursing care as challenges in hospitals. Moreover, nursing care process has been investigated.
\end{abstract}

Keywords: Executive obstacle; Nursing process nursing

\section{Method}

\section{Action research}

This study was conducted using quantity method focusing on content analysis at kashani hospital in Isfahan. All data was gathered by asking open questions from 40 employees in neurology and epilepsy ward. This study was done using study- together method. In this way, a group of people who might be employees in the same profession, offer specific dimension of their own function.

Every cycle of collaborative research includes four stages.

First stage: It is dedicated to rethinking; a group of people select a way for observation and documentation for their individual experience. Then one practical program is planned to do action research. The collaborative group has a better understanding of other career repetitive cycle of rethinking and they will be able to change situation via doing agreements.

Second phase: Participants have the role of being researched. They start to do the unanimous practice.

Third phase: Participants drown in their job that cause they might face with unpredictable experience or they will get new insights.

Fourth phase: This stage starts in an appropriate time after second and third phases and it is dedicated to rethinking. In this stage, the members of the group get to gather to share their information and experience.

Final phase: Participants may modify or develop the action form and gathering data.

The study was conducted in neurology and epilepsy ward at kashani hospital affiliated to the Isfahan University of Medical Science. The study was conducted from February 30th to March 30th,2017. This survey was conducted in neurology ward included the head nurse,20 nurses and 4 nurses assistant, and in epilepsy ward it included the head nurse and 12 nurses. The proportion of nurses to patients was fixed. In the morning it was 5 to16, in the afternoon 3 to 16 and at night 3 to 16 nurses took care of the patients in every shift. In addition, they did other duties. A member of his or her family could be with the patient during he or she is hospitalized.

Ten nurses made up that group as well as two researcher starters, that is, head nurse and researcher. All those clinical nurses had a bachelor's degree except one nurse assistant. The range of their age was 23 to 40 and the work experience was from less than 1 year to 20 years. Participating in the action research was optional and the participants could give up at any stage. They were trusted that not participating in this survey was acceptable, and it did not have any negative effects on their profession, and it would 
be published with no names. The second cycle was conducted from December 30th to February 2017. In the previous cycle, to empower nurses to do nursing process, it was attempted to have personal concentration to deal with barriers. Participants could list nursing process barriers according to the unanimous plan. And they selected an appropriate solution through the suggestions available.

Following factors were listed according to the personal responses:

1. shortage of nursing staff

2. imbalance between nurses and patients

3. nursing process as a time-consuming action

4. the speed and ease of the current nursing implementation process.

5. Lack of practical pattern based on nursing process

6. Lack of checklist or lack of reporting tools for doing nursing process.

7. Lack of evaluation action based on nursing process.

8. Not accepting nursing process by other treatment staff.

9. Lack of enough motivation and nursing care implementation based on traditional pattern.

10. Lack of culture context in clients.

11. not clarifying the importance of nursing implementation process.

12. not having enough points for nursing implementation process.

Prolonged engagement of participants helped stages of action, rethinking and also interpreting findings. In the stage of rethinking, focused group discussion was chosen for gathering data. In this way, different points of view were engaged to discuss, and participants were given opportunity to offer some questions and answer based on their experiences. Based on the member's agreement, discussion sessions were held once a week at the end of morning shift at 2:00p.m. Group discussion provided maximum presence of morning and afternoon nurses. After not having any new information in the third meeting, the rethinking process finished in that step. The data reached through focused- group discussion was analyzed Using quality context analyzing and focusing on contracts. The above obstacle was shared with educational supervisor and the following suggestions were given to her and the best solution was selected. (application of findings at clinic)

1) Locating the new internal and foreign nursing findings in nursing board in all wards in the hospital.

2) This data included continuous content based on the stateof-the art findings.

3) Holding nursing workshops based on evidence.

4) introducing internal and foreign nursing about designed patterns are as on -the job-training

5) Nursing participation in the nursing care plan based on nursing process and a high-quality nursing implementation.

6) Providing care standards based on nursing process.

7) providing the proportion of a and nurse and have a reasonable pay to nurse.

8) providing theoretical leaflets and booklets, and practical pattern based on nursing process in hospitals.

9) guiding action research in nursing process implementation.

10) accelerating action research process using action research implementation for planning and participating in nursing process.

Changing organization has some obstacles including:

1. limitation of workforce interested in cooperating.

2. personal and organizational resistance to changes

3. cultural weakness in teamwork implementation

4. disappointment and leaving participants from qualitative study.

5. limitation of time, budget and personal facilities (etc.)

There were some limits to overcome these obstacles. Also, expert's recommendation was a planned change process by motivating and omitting resistance.

Including:

1) negotiation and creating preparation in senior managers.

2) create a kind of support for change factors.

3) Determining a clear mission and vision for participants.

4) Reinforcing new behaviors and developing skills and essential merit in nurses

Participants could analyze the obstacles via teamwork and rethinking, and they could overcome barriers in nursing process by the looking- back trend. They did anything necessary to change the function. Rethinking can be done by analyzing, and also a comment could be achieved for playing future action. Based on findings, the most important barriers were imbalance between number of nursing staff and patients, nursing implementation as a time- consuming action, lack of activity evaluation based on nursing process and lack of appropriate pattern in nursing process implementation. If a regular system in nursing process, based on a known pattern (similar to nursing process) is set practically, we can promote quality and quantity of nursing care.

\section{Discussion and Result}

According to findings, the most important barriers are imbalance between number of nurses and patients, being time consuming of nursing process implementation. Absence of evaluating activities based on nursing process, absence of appropriate pattern in nursing process. If we can set a regular system for nursing health care based on a known pattern practically, the quality and quantity of process as a result can be improved. 
The final purpose of high-quality nursing care is to improve patient situation and return them to the society.

Increasing quality of nursing care makes patients ready to return to their normal life more quickly and prevent them being hospitalized again. One of the most significant approaches to improve the quality of nursing care is utilize standard of nursing care.

What's more, a nurse can be a professional and efficient person when they are able to use these approaches practically. One of these standards is to utilize nursing care process. The purpose is to identify the health situation of the patient and their current problems or social problems (kaji \& coworker). In the other words, nursing process goal is to assess patient's problems and nursing diagnosis and assessment of real and potential response of clients to states of their health and disease (2004 potter \& coworker). Nursing process was at first introduced by Orlando (1961) as a practical instrument for nursing function, and nowadays it has turned to a basic framework for clinical training function. Also nursing process is the basic and essential concept in nursing (potter \& coworker 2009). Nursing process is applicable in the most clinical environments. If nursing care is done based on this process, clients receive the best care in the shortest possible time (timby and coworker 2009) [1-3].

Since the quality of care was introduced as the first priority in nursing in 21st century and it is still more important than any other goals, implementation of nursing process seems more important than ever (melis \& coworker) and neglecting it in hospitals will create many problems that cause to decrease job satisfaction, lack of correct evaluation of nursing, nursing downgrade scientifically and practically, decreasing the quality of care, low attention of some authorities, devaluation of nursing profession over dependence on doctors, obedience blindly, one- dimension care, decreasing in dependence of patients and finally spending plenty of costs due to repetitive acts. (noohi \& coworker) What is the barrier to improve the quality and quantity of care is lack of utilizing appropriate theatrical pattern that has environmental clinical facility. If we can set one regular system to present nursing care totally and practically, we can improve the quality and quantity of nursing care. (noohi \& coworker) [4-7].

\section{Acknowledgement}

I would like to appreciate the guidance given by engineer mahdi shafiei in my article that has improved my article and thanks to his comment and advice for translating my article.

\section{Conflict of Interest}

No conflict of interest.

\section{References}

1. Shoorideh F, Hasani P (1390) Action research A way to improve the quality of nursing services. Nursing Research 6(21): 48-58.

2. Burns, N, Grove SK (2005) Nursing research: conduct, critique \& utilization $\left(5^{\text {th }}\right.$ edn $)$, USA.

3. Akbari Kaji M, Farmahani Farahani B (2011) The effect of nursing process education on nursing care quality of schizophrenic patients. Feyz 15(1): 32-37.

4. Potter P, Boxerman S, Wolf L, Marshall J (2004) Mapping the nursing process: a new approach for understanding the work of nursing. JONA 34: 101-109.

5. Melis AE (2009) Theoretical nursing: development\& progress. In: Shokati Ahmad Abadi Tehran: Afrang (Eds.).

6. Timby BK (2009) Fundamental nursing skills and concepts PKG. Philadelphia: Lippincott Williams \& Wilkins.

7. Noohi S, Karimi H, Najmai E (2010) Application obstacles of nursing process from view of the nursing managers and interns in Kerman University of Medical Sciences. Journal of KUMS 1: 52-58. 